International Journal of Advanced Studies in Humanities and Social Science (IJASHSS)

Available online at http://www.ijashss.com

Volume 8, Issue 1 (2019) pp. 71-78

Original Article

\title{
The Effect of Education on Social Acceptance and Happiness by High School Students in Sabzevar City
}

\author{
Maryam Motakef far*1, Mosavi Alizadeh², Hasan Nodehi² \\ ${ }^{1}$ Corresponding Author, Department of Counseling on school, Quchan Branch, Islamic Azad \\ University, Quchan, Iran \\ 2Department of Counseling on school, Quchan Branch, Islamic Azad University, Quchan, Iran
}

Received: 24 October 2018, Revised: 05 December 2018, Accepted: 20 December 2018

\section{ABSTRACT}

The present study investigated the effect of teaching happiness by Fordyce method to students on their social acceptance and happiness. The subjects participating in the study were 30 female high school students in 1391-1392 at sabzevar high schools. The subjects were selected using random sampling procedures. Then, they were randomly assigned to experimental groups. Oxford social acceptance and happiness questionnaire was used to gather the necessary data. The experimental group received 8 sessions instruction on happiness. The oxford questionnaire was assigned to both groups. The gather data were analyzed using analysis of variances. The results showed that happiness instruction significantly increased life satisfaction, self-esteem satisfaction, self well fare and good temperedness of the students.

Keywords: Effectiveness, Teaching Happiness by Fordyce Method, Social Acceptance.

\section{Introduction}

Human has been seeking how he can have a better life and what makes him more satisfied and by which mechanism he can enjoy more from his life. All this is related to the concept of happiness and joy somehow (Dickey, 1999). With the introduction of the increasing importance happiness of in mental health and also its impact on human mental powers to deal with the complexity and problems of today's world, attention of researchers, scholars, and even commons than that has changed. Research has shown that happiness; regardless how they obtain, can improve health (Achat, 2000). People, who are happy, feel more secure, decide easier, have more cooperative spirit and feel satisfied to people who live with (Myers, 2000).

The scientific study of emotional tranquility has been begun recently, but the theories about mystery of the Happiness have an ancient history (Nodding, 2003). Ancient Greek philosophers have said and written about the subject of happiness a lot. They believe that happiness should be search leisurely and with clever ideas. Cicero (106 to 43 B.C.) believed "Happy fool and, sad wise does not exist (Alberktsen, 2003). The Greeks and Cicero's point of view, enjoying of life is more associated with the mind rather than physical aspects of it. Relaxation and happiness in life are summarized in being free from sensual 
desires and material development. Epicurean Philosophers and the Stoics changed the happiness song. According to Epicurus (34 to 270 BC.) happiness was shorten in simple living and peace of mind. In his point of view wise people look at the past with pride and respect, use joy of the moment and look recklessly to eternal future. Stoicism sought happiness in virtue and piety (Eddingtonm, 2004). They believed it was the happiness to distinguish the good from the bad, what we fear and what not hesitate to tackle and control our carnal lusts. What best we accept the existing conditions do not let the change of heart at stake. Being happy and have desire to live happily is the common denominator of all human beings. But it seems the young people have more interest of this features than others. Young people according to the requirements of their age they want an exciting and happy world in nature. But some looks at these features in a way that as if they have committed a great sin. In the meantime, some believe there is nothing empty and emptiness is not useful even if it is a joy (Petrides, 2000). They believe even revel should be motivated and have a purpose, While the joy itself is noble motivation and goal (Lichter, 2010).

The question is whether we have the happy society? This is a question that cannot be answered in theoretical discussions and needs official statistics. Unfortunately, so far no research has been done on measuring happiness in our society but statistics such as divorce, addiction, suicide, mental illness, neurological disorders, interpersonal conflicts and ethnic employment rate, the rate of relative prosperity and social exploitation ... It does not indicate a satisfactory situation. If we want to really understand and to say that the youth of our community are happy, we need a scientific study (Flora, Carlin, 2009). But what is undeniable that our society is an Islamic society and has fundamental differences with other communities that is due to the shackles of religion-oriented, guided by faith and religion, and should also be expected to have a society with tangible joy while this freshness is not visible; Some unofficial and normal statistics indicate the dropouts, runaways, immigration, falsely jobs and others can indicate a lot of things within our society and the happiness of youth. And necessary steps to be taken seriously in this regard. Iranian youth in the community suffer from shortcomings. They need a full of hope and happy environment for the growth and excellence (Fujita, 2011). But could it be expected given the specific problem of the Iranian youth today they would be happy? Is it possible without having a proper job, living in a troubled family and a deep sense of loneliness they still feel happy? Basically what are the factors of the happiness of mankind, and especially the youth who are the future of the country?!

\section{Research Method}

This study based on purpose is practical and based on method is a quasiexperimental study. Study design is pretest - post-test with control group. The study population included secondary high school student girls in Sabzevar city. Total number of Government Girls High School of Sabzevar city is 14 high schools. The total numbers of female students studying in these schools are 3,500. Group of subjects in this study was 200 female high school students in Sabzevar city. Sampling method was available samples. Of the 200 students, 38 students who responded to the questionnaire scores and low social acceptance and happiness were selected and were divided into two groups of 18 , 
after a loss in the experimental group, 15 patients in each group analyzed experimental group was trained happy by Fordyce methods, but the control group (n $=15$ ) were given no training. Data for the study was obtained using a, social acceptance and happiness questionnaire. After determining the required sample size for each string, beginning at the city Department of Education, Sabzevar, while sharing this research with experts and authorities, schools, obtaining the license to do research was in the next stage 3 schools see, after coordination with the school principal was asked to share a part of class time, writer would be assisted in conducting research. The process of gathering information and data needed has been done for both individual and group research. In this study descriptive and inferential statistical data analysis was performed using SPSS software. Descriptive statistics were used to describe the materials cover includes tables, diagrams, frequency distribution, mean, standard deviation and for the analysis of covariance was used to analyze the data. Pretest scores for social acceptance and happiness in this analysis as control variables, social acceptance and happiness posttest scores as the dependent variable and the level of social acceptance and happiness Fordyce happiness teaching method, students were independent variables.

Table 1. Descriptive statistics comparing happiness and social acceptance in both experimental and control groups.

\begin{tabular}{|c|c|c|c|c|}
\hline $\begin{array}{c}\text { Social } \\
\text { acceptance }\end{array}$ & Happiness & & & \\
\hline $10 / \cdot 7$ & rV/I & Mean & & \\
\hline$r / \cdot \Lambda$ & \urcorner$/ \wedge \mathrm{V}$ & $\begin{array}{l}\text { Standard } \\
\text { deviation }\end{array}$ & Pre test & Control group \\
\hline 10/V & 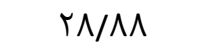 & Mean & & \\
\hline$r / T V$ & $7 / 19$ & $\begin{array}{l}\text { Standard } \\
\text { Deviation }\end{array}$ & Post test & \\
\hline $\mid r / \varepsilon\rceil$ & ז / & Mean & & \\
\hline r/or & $1 \cdot / \cdot 7$ & $\begin{array}{l}\text { Standard } \\
\text { deviation }\end{array}$ & Pre test & $\begin{array}{l}\text { Experimental } \\
\text { group }\end{array}$ \\
\hline TI/VT & $\varepsilon \pi / \varepsilon$ & Mean & & \\
\hline$r / \mu \varepsilon$ & $1 / 00$ & $\begin{array}{l}\text { Standard } \\
\text { deviation }\end{array}$ & Post test & \\
\hline
\end{tabular}

Demographic data showed that the sample consisted of 30 high school girls who have been in Sabzevar city have been into two groups (experimental and Control) randomly to the volume of 15 people. Descriptive data from the survey instrument is provided in the table above.

The results show that the average of the two experimental and control groups in the social acceptance questionnaire in pretest have small differences that cannot be considered significantly. In most cases where there is little difference, the mean of the experimental group were lower. These findings imply that participants in the experimental group in terms of social acceptance and happiness are in worse condition.

The mean pre-test and post-test experimental group increased. These findings imply that the companies participants of the experimental group after attending therapy sessions, in order 
to target interventions (improving social acceptance and happiness) have changed.

The mean of pre-test and post-test control group of the study was increased. In other words, this group of study participants when experimental group took therapy sessions, has not experienced any treatment intervention, and has a slight increase in the amount of the social acceptance and happiness. Comparison of experimental and control groups at posttest shows that the mean of the experimental group is higher than control group. These findings imply that participants in the experimental group after treatment had more social acceptance and happiness than the control group participants.

Table 2. Variance analysis of the effect of happiness training on the social acceptance in the control group and the experimental group

\begin{tabular}{|c|c|c|c|c|c|}
\hline $\begin{array}{c}\text { Significance } \\
\text { level }\end{array}$ & F proportion & Mean Square & $\begin{array}{l}\text { Freedom } \\
\text { degree }\end{array}$ & $\begin{array}{l}\text { Sum of } \\
\text { squares }\end{array}$ & \\
\hline$\cdot / \cdots 1$ & $\varepsilon r / \cdot \Lambda\rceil$ & $91 / \varepsilon 1 r$ & 1 & $91 / \varepsilon 11$ & Isolated Model \\
\hline \multirow[t]{3}{*}{.$/ .1$} & 10N/Tro & 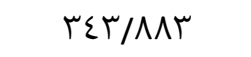 & 1 & 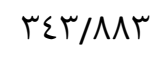 & Group \\
\hline & & r/IVT & TV & $0 \wedge / า \varepsilon \varepsilon$ & Error \\
\hline & & & $r$. & $1.90 \varepsilon$ & Total \\
\hline
\end{tabular}

Given that the sig $=0 / 001$ is less than $\alpha$ $=0 / 05$; that means the test statistic falls in $\mathrm{H} 1$ area, so the hypothesis $\mathrm{H} 0$ is rejected and $\mathrm{H} 1$ is accepted that the claim is achieved.

There is a significant relationship between the independent variable (happiness Fordyce method) and the dependent variable (social acceptance) ( $\operatorname{sig}=0 / 001$ is less than $\alpha=0 / 05$ ).

There is a significant relationship between pretest auxiliary variable (moderator variable) and the dependent variable (social acceptance), (Value is sig = $0 / 001$ and less than $\alpha=0.05$ ).

Table 3. Covariance analysis of the effects of happiness training on students' happiness in the control group and the experimental group

\begin{tabular}{|c|c|c|c|c|c|}
\hline $\begin{array}{c}\text { Significance } \\
\text { Level }\end{array}$ & F proportion & Mean Square & $\begin{array}{l}\text { Freedom } \\
\text { Degree }\end{array}$ & $\begin{array}{l}\text { Sum of } \\
\text { squares }\end{array}$ & \\
\hline.$/ \cdot 1$ & rт/IV & $\varepsilon \wedge\urcorner / \cdots 1$ & 1 & $\varepsilon \wedge\urcorner / \cdots 1$ & $\begin{array}{c}\text { Isolated } \\
\text { model }\end{array}$ \\
\hline \multirow[t]{3}{*}{$\cdot / \cdots 1$} & Vา/r々r & 110\% & 1 & $110 \% / .14$ & Group \\
\hline & & 10/1r & rV & $\varepsilon \cdot \Lambda / \mu r$. & Error \\
\hline & & & r. & ETMIE & Total \\
\hline
\end{tabular}

Given that the $\operatorname{sig}=0 / 001$ is less than $\alpha$ $=0 / 05$, that means the test statistic falls in $\mathrm{H} 1$ area, so the hypothesis $\mathrm{H} 0$ is rejected and $\mathrm{H} 1$ is accepted that the researcher's claim is achieved.

There is a significant relationship between the independent variable (happiness Fordyce method) and the dependent variable (Students' happiness) ( $\operatorname{sig}=0 / 001$ is less than $\alpha=0 / 05$ ).

There is a significant relationship between pretest auxiliary variable (moderator variable) and the dependent variable (Students' happiness), (Value is $\operatorname{sig}=0 / 001$ and less than $\alpha=0.05$ ). 


\section{Results}

Some studies associated with happiness and achieving indicators such success, mental health and well-being, increase in job activity and high mood has been conducted which some of them can be noted such as studies conducted by Rathy and Rastoujy (2008), Chan (2007), Kooproosvaf (2006), Sharpe (2007), Petraydz and colleagues (2000), Vytresou (2001), Yaghoubi (1387), Jowkar (1386), Golestan Jahromi (1383) and poorzarehi (1382) that all of them revealed significant correlation between happiness, life satisfaction, mental health and happiness and those who reported higher happiness in dealing with life's problems and solve them pay higher morale and greater use of problem solving in them.

The results obtained (Mohammadi, 1386) about the effects of happiness on public health education students did not show a significant difference in the interaction effect of gender and group; In other words, happiness training was conducted for male and female students, one of whom was an effective public health students to a level of increased. Therefore third research hypothesis was not confirmed.

In general, according to the results of Myers (2007) Adeengton and Schumann (2004) and Fujita and others (1991) about the fact that women tend to experience more negative emotions and positive emotions are more sensitive and therefore more are seeking treatment, it was expected that the effect of happiness training on happiness of male and female students be different which further evaluation is needed.

In this study, the students showed interest in attending meetings and actively engaged in performing tasks, and this, while five students previously didn't believed in psychological principles and it did but by attending educational sessions now at these meetings, they gradually formed in the belief that education can be effective and is able to change them. Some of them stated that these sessions are completely practical tips learned in their lives and have a positive effect on their happiness, while before attending these meetings; they didn't have these useful information.

However, in this study we tried to do this project as much as possible accurately and the obtained data would be reported and analyzed transparently. It seems that in order to clarify the effectiveness of happiness training by Fordyce method in increasing happiness and social acceptance in female adolescents in Iranian society and culture, it is necessary that more research to be conducted in this field.

\section{Suggestions}

1 - In order to comment definitely and better on the results of this study, it is suggested further research in this field in different samples such as students or be done to the other can be provision of sections comparison to generalize results more. Actually doing research involving factors such as different subcultures, religion, religious orientation, economic status - social and family can share in each of these variables in increasing social acceptance and happiness to a certain extent.

2- To study the relationship in order to control and put confounding variables as moderators done.

3- It is recommended in future studies, the relationship between time spent on social acceptance and happiness teaching students to be measured.

4- According to the measuring instrument was a questionnaire, it is recommended that future dissertation research other 
tools such as interviews, observations, and ... Alongside this tool is used to validate the results can be generalized outside bark.

\section{Practical Suggestions}

1 - Due to the importance of social acceptance and happiness in young girls vulnerable and sensitive to this class of lack of social acceptance of this period of life, including social acceptance and happiness in the form of skills training programs, workshops, is proposed.

2 - Informing families, teaching parents to educate their children with greater social acceptance and happiness in order to prevent and reduce the social harm caused by shyness can be an effective way.

3 - It is recommended, these results provide counselors and psychologists to be so aware of the situation and the impact of these factors on social acceptance and happiness of students, and to provide the promotion of these two variables.

4- Training workshops for parents on child care and schools and cultural centers.

5 - The use of mass media, especially television, to increase parents' awareness of the increasing social acceptance of female skills.

\section{Limitations and Problems of Research}

Do any kind of research and intervention research, especially due to external and internal factors affecting, creates limitation which is uncontrollable. Therefore, the effects of these external factors can have a significant impact on results.

Limitations of this study can be summarized as follows:

1 - Limitation by the effects of confounding variables: In his acceptance at school and family environment of students and several factors may influence the possibility that the researcher cannot control all the variables. And because of this study is limited by the conditions of this study. Therefore, the interpretation of results with regard to the current situation and the effects of unwanted variables can be given.

2- Due to the limited response of subjects (Kerlinjer, 1986): High school girl student responses (respondents to the questionnaire) for various reasons, including lack of willingness to respond and so it was with bias and this can be associated with a lack of accuracy in data collection. This situation is completely out of control research and interpretation of results should also be considered for this position.

3 - In this study, pre-test and post-test was administered at an interval of about a month. Therefore maintain or change social acceptance samples are not available after completion of the training program.

4 - In this study, only female high school students were concerned that it would affect the generalizability of the study.

\section{References}

Achat. H., Kawachi, I., Spiro, A., Demolles, D.A., and Sparrow, D. (2000). Happiness and as Predictor of physical and mental Health functioning. The normative aging study. Annals of Bechavioral medicine, 22 (2): 127- 130.

Alberktsen, G. (2003). Happiness and related factors in pregnant women, deparyment of psychiatare, faculty of mediene, chulalongkorn university, Bangkok, Thailand.

Argyle, J. and M. Hill, P. (2003). Religious experiences and their relationship with Happiness in adult and olds.

Astin, J.A., Beckner, W., Soeken, K., Hochberg, M.C. nad Berman, B. (2002). 
Psychological intervention for rheumatoid arthritis: A meta- analysis of randomized controlled trials. Arthritis and Rheumatism, 47, 291-302.

Biddle, S. and Mutri, N. (1991). Psychology of physical activity and exercise. London: Springer/Tavistock/Routledge.

Bradburn, N.M. (2012). The Structure of Psychological well-being. Chicago; Aldine publishing company

Davis, P.A., and Leonard, B.G. (2011). Influence of emotional intensity and Frequency of Positive and negative events on depression. European Journal of Personality Assessment, 15, 106- 116.

Diener, E. (2002). Frequently Asked question (FAQ'S) about subjective wellbeing (Happiness and life satisfaction). A printer for report and new comers. http://www./s.psych.uivc.edu/ediener/fag.html.

Eddington, N. and Shuman R. (2004). Subjective Well-being. Presented by continuity psychology education.

Fava, G.A., Fatanelli, C., lazzaro, M., conti, S. and Grandi, S. (2012). Well-being therapy a novel psychotherapeutic approach for residual symptoms of affective disorders. Psychological Medicine, 28, 475-480.

Flora, C. (2009). The pursuit of Happiness. Psychology today magazine. Article tD: 4738. http: // www. Psychology today. Com / articles / index. Page :4.

Fujita, F., Diener, E. and Sandvik, E. (2011). Gender differences in negative affect and well-being: The case for emotional intensity, Jounal of Personality and Social Psychology, 61, 427-434.
Headey, B.W., and Wearing, A. (1992). Understanding Happiness.Melbourne, Australia: Longman Cheshire.

Hills, P., Argyle, M., and Reeves, R. (2000). Individual differences in leisure satisfactions: an investigation of four theories of leisure motivation. Personality and Individual Differences, 28, 763- 779.

Jayasvasti, K. (2005). Happiness and related factors in pregnant women,deparyment of psychiatry, faculty of mediene, chulalongkorn university, Bangkok, Thailand.

Kawamato, (2012). Happiness and background factor in community dwelling older person. D epartment of Intenet medicine, Nomura municipal Hospital.

Ketchian, L. (2006). Your keys to Happiness PK@ aol. com. The website www. Happiness club. com

King, L.A., and Napa, C.K. (2008). What makes a life good? Journal of Personality and Social Psychology, 75, 156- 165.

Kowal, J., L.C. (2006). Increasing the happiness of outpatient cancer patients. Unpublished masters thesis, University of Edmunton, Canada.

Lichter, S., Haye, K. and Kamman, R. (2010). Increasing happiness through cog native training. Newzealand Psychologist, 9, 57-64.

Lyumbomirsky, S., Sheldon, K.M. and Schkad, D. (2005). Pursuing happiness: The General Psychology, 9, 111-131.

Lyumbomirsky, S. and Sheldon, K.M. (2005). Achieving sustainable new happiness: Prospects, practice and prescriptions. in P.A., Linley, \& S. Joseph. Positive psychology. 
Mayer, J.D., Salovey, P. (2004). A further consideration of issues of emotionalintelligence. Psychological Inquiry, 15(3), 249- 255.

Nodding. N. (2003). Happiness and Education New York: Cambridge university press.

Okun, M.A., Stock, W.A., Haring, M.J., and Witten R.A. (2011). Health and subjective well- being: a meta- analysis. International Journal of Aging and Human Development, 19, 111- 132.

Pernegar, T.V. (2004). Health and happiness in young swiss adults, Qulity of care until. Geneva university Hospital, Geneva, Switzerland.

Petrides, F. (2000). Gender difference in measured and self-estimated traitemotional intelligence. Journal articles.

Petrides, K.V. and Furnham. (2000). Gender difference in measured and self -estimated trait emotional intelligence. Journal articles personality, 10, 45-59.

Rathi, N. and Rastogi, R. (2008). Effect of emotional intelligence on occupational self- efficiency. The ICfia Journal of organizational Behavior, 7(2), 46-56.

Ryff, C.D. (2011). Happiness is everything, or is it? Explorations on the meaning of Psychological well- being. Journal of Personality and Social Psychology, 57, 1069-1081.

How to cite this article: Maryam Motakef far, Mosavi Alizadeh, Hasan Nodehi, The Effect of Education on Social Acceptance and Happiness by High School Students in Sabzevar City. International Journal of Advanced Studies in Humanities and Social Science, 2019, 8(1), 71-78. http://www.ijashssjournal.com/article 84110.html 